\title{
Association of Physical Activity with Late-life Mobility Limitation among Women with Total Joint Replacement for Knee or Hip Osteoarthritis
}

\author{
Aladdin H. Shadyab, Charles B. Eaton, Wenjun Li, and Andrea Z. LaCroix
}

\begin{abstract}
Objective. To examine the association between leisure-time physical activity (PA) and survival to age 85 with mobility limitation or death before age 85 after total knee (TKR) or total hip replacement (THR) for osteoarthritis (OA).

Methods. This was a prospective study among participants from the Women's Health Initiative (WHI), recruited 1993-1998 (baseline age 65-79 yrs) and followed through 2012. Medicare claims data were linked to WHI data to determine TKR $(\mathrm{n}=1986)$ and THR $(\mathrm{n}=1034)$. Self-reported PA was collected before total joint replacement (TJR).

Results. Women who were physically inactive before THR had the highest risk of mobility limitation at age 85 (OR 2.36, 95\% CI 1.30-4.26) compared with women who had the highest amount of PA [> 17.42 metabolic equivalent of task (MET)-hrs/week]. Women who reported no moderate to vigorous PA (MVPA) before THR had the strongest risk of mobility limitation (OR 2.00, 95\% CI 1.24-3.22) compared with women with the highest level of MPVA ( $\geq 15$ MET-hrs/week). Women who were physically inactive before TKR had the highest risk of mobility limitation (OR 1.68, 95\% CI 1.15-2.45) compared with women who had the highest PA level. Women who reported no MVPA before TKR had the strongest risk of mobility limitation (OR 1.60, 95\% CI 1.16-2.19) compared with women with the highest level of MPVA. There were significant dose-response associations of lower PA levels with increased risk of late-life mobility limitation and death.

Conclusion. Women with lower PA levels before TJR were more likely to experience mobility limitation in late life following TJR for hip or knee OA. (First Release June 1 2018; J Rheumatol 2018;45:1180-7; doi:10.3899/jrheum.171136)
\end{abstract}

Key Indexing Terms:

ARTHROPLASTY

PHYSICAL ACTIVITY

OSTEOARTHRITIS

KNEE
FUNCTIONAL OUTCOMES

HIP

\footnotetext{
From the Division of Epidemiology, Department of Family Medicine and Public Health, University of California San Diego School of Medicine, La Jolla, California; Center for Primary Care and Prevention, Memorial Hospital of Rhode Island and Department of Family Medicine, Warren Alpert Medical School, Brown University, Providence, Rhode Island; Division of Preventive and Behavioral Medicine, Department of Medicine, University of Massachusetts Medical School, Worcester, Massachusetts, USA.

Supported by the US National Institute of Arthritis and Musculoskeletal and Skin Diseases (grant T32 AR064194 to AHS), the US National Heart, Lung, and Blood Institute (contracts HHSN268201100046C, HHSN268201100001C, HHSN268201100002C, HHSN268201100003C, HHSN268201100004C, and HHSN271201100004C), and the Women's Health Center of Excellence at the University of California, San Diego School of Medicine. The National Heart, Lung, and Blood Institute has representation on the Women's Health Initiative Steering Committee, which governed the design and conduct of the study, the interpretation of the data, and preparation and approval of manuscripts.

A.H. Shadyab, PhD, Postdoctoral Fellow, Division of Epidemiology, Department of Family Medicine and Public Health, University of California San Diego School of Medicine; C.B. Eaton, MD, MS, Professor, Center for Primary Care and Prevention, Memorial Hospital of Rhode Island and Department of Family Medicine, Warren Alpert Medical School, Brown University; W. Li, PhD, Associate Professor, Division of Preventive and Behavioral Medicine, Department of Medicine, University of Massachusetts Medical School; A.Z. LaCroix, PhD, Professor, Division of Epidemiology, Department of Family Medicine and Public Health, University of California San Diego School of Medicine.
}

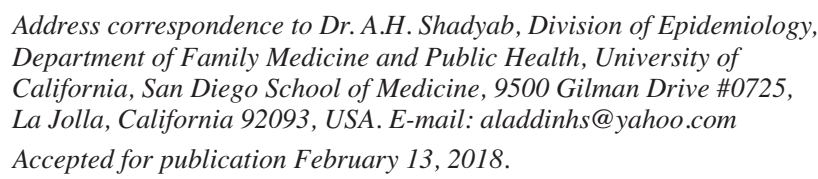
Department of Family Medicine and Public Health, University of California, San Diego School of Medicine, 9500 Gilman Drive \#0725, La Jolla, California 92093, USA.E-mail: aladdinhs@yahoo.com Accepted for publication February 13, 2018.

Osteoarthritis (OA) is a major cause of disability among older people, affecting 1 in 8 adults ${ }^{1,2}$. Total joint replacement (TJR) surgery, including total hip (THR) and total knee replacements (TKR), may be considered in cases of severe $\mathrm{OA}^{3,4}$. More than 1 million THR and TKR are performed annually in the United States ${ }^{5}$. With the growth of the aging population and rising OA prevalence, use of THR and TKR will increase 4 -fold by $2030^{2,6}$. However, few studies have followed patients with OA and TJR recipients prospectively into late life to understand patterns of functional changes and to define strategies to prevent mobility limitation among those who survive into very old age.

Physical activity (PA) has been recommended for the successful management of OA and may improve physical function among patients with severe $\mathrm{OA}^{7,8,9,10,11,12}$. In a randomized controlled trial among older adults with knee 
OA, participation in an aerobic exercise program was associated with less physical disability, less knee pain, and better physical performance 18 months after the trial ${ }^{10}$. Some studies have observed that PA may lead to better function before TJR ${ }^{13,14,15}$. Men and women scheduled to undergo THR who participated in a 6-week exercise program showed greater improvements in physical function scores before surgery ${ }^{15}$. However, little attention has focused on the relationship between PA before TJR and longterm functional health after surgery $15,16,17,18$. Previous studies yielded conflicting results on the potential effect of presurgery exercise programs on postsurgery functional outcomes among TJR patients. Two prior studies observed that presurgery PA did not improve functional outcomes a year after surgery ${ }^{15,16}$, but a randomized controlled trial showed that an 8-week, tailored exercise program before THR resulted in better physical function 6 months after surgery ${ }^{17}$.

Maintaining mobility in old age is a key component of successful aging and is an important public health goal for patients with $\mathrm{OA}^{1,19}$. Previous studies among the general population showed that regular PA is associated with better mobility and physical function later in life $20,21,22,23,24$. However, to our knowledge, no study has determined whether preoperative PA is associated with maintaining mobility in old age among a cohort of patients who underwent TJR for OA. A potential link would strengthen the evidence base supporting increase of PA levels before TJR among patients with hip and knee OA.

Using prospective data from the Women's Health Initiative (WHI), we examined associations between leisure-time PA levels before TJR and survival to age 85 with mobility limitation or death before age 85 among women who underwent THR or TKR for OA.

\section{MATERIALS AND METHODS}

Study population and design. The WHI is a longitudinal study investigating determinants of chronic diseases in women. The study design has been previously described $^{25}$. Briefly, a cohort of 161,808 postmenopausal women aged 50 to 79 years was recruited from 40 US clinical centers from 1993 to 1998. Women participated in $\geq 1$ of 3 clinical trials $(n=68,133)$, including 1 of 2 Hormone Therapy trials, or an observational study $(\mathrm{n}=93,676)$. In 2005, $77 \%$ of eligible women agreed to be followed through 2010 in the first extension study. In $2010,87 \%$ of eligible women enrolled in an additional 5 years of followup in the second extension study. Our study was exclusive to women ages 65 years and older who were continuously enrolled in fee-for-service Medicare from baseline until the end of followup in 2012, and who underwent THR $(n=1034)$ or TKR $(n=1986)$ for OA at any time during followup (see Supplementary Methods, and Supplementary Table 1, and Supplementary Figures 1 and 2, available with the online version of this article). Medicare claims data were used to identify THR and TKR. All participants provided written informed consent. This study complied with the Declaration of Helsinki and was approved by the Human Research Protections Program at the University of California, San Diego (Protocol No. 161486).

Physical activity assessment. At the baseline visit, women completed a questionnaire assessing usual participation in leisure-time PA. The questionnaire was completed on average 6.7 (SD 3.7) years before TJR. The questionnaire has acceptable reliability, with high intraclass correlation coefficients for moderate to vigorous PA (MVPA; $r=0.77$ ) and total PA $(\mathrm{r}=0.76)^{26}$. Participants were asked how often they walk outside the home for more than $10 \mathrm{~min}$ without stopping, the duration of walking, and walking speed. Frequency categories were rarely or never, 1-3 times/month, 1 time/week, 2-3 times/week, 4-6 times/week, and $\geq 7$ times/week. Duration categories for walking included $<20 \mathrm{~min}, 20-39 \mathrm{~min}, 40-59 \mathrm{~min}$, and $\geq 1 \mathrm{~h}$. Categories for walking speed included casual (slower than normal), strolling $[<2 \mathrm{miles} / \mathrm{h}(\mathrm{mph})]$, average or normal (2-3 mph), fairly fast (3-4 $\mathrm{mph}$ ), and very fast ( $>4 \mathrm{mph}$ ). Participants reported how often and for how long at each session they participated in activities of various intensity: light (e.g., slow dancing, bowling, and golf), moderate (e.g., biking outdoors, calisthenics, and easy swimming), and vigorous (i.e., that increased heart rate and produced sweating such as aerobics, aerobic dancing, and jogging). Frequency categories were none and 1, 2, 3, 4, or $\geq 5$ days/week. Duration categories were $<20 \mathrm{~min}, 20-39 \mathrm{~min}, 40-59 \mathrm{~min}$, and $\geq 1 \mathrm{~h}$.

Midpoint values for ranges of frequency and duration of PA sessions were imputed, and the product of frequency and duration was used to create "hours/week (h/wk)" variables. Metabolic equivalent of task (MET) values were assigned for vigorous, moderate, and light activities as 7, 4, and 3 MET, respectively ${ }^{27}$. MET values for walking were assigned as 5, 4, 3, and 2 for very fast, fast, average or normal, and casual, respectively. The MET level was then multiplied by $\mathrm{h} / \mathrm{wk}$ to compute separate variables for walking, light, moderate, and vigorous activities in MET-h/wk. MVPA was computed as the sum of average or normal and fast walking, moderate activity, and vigorous activity. Total PA was computed by summing across all activities.

Total PA and walking were divided into 4 categories, including 0 MET-h/wk and tertiles for the remainder of the data. MVPA was categorized as $0,>0$ to $<7.5,7.5$ to $<15$, and $\geq 15 \mathrm{MET}$ - $\mathrm{h} / \mathrm{wk}$ according to current federal guidelines recommending $\geq 7.5 \mathrm{MET}-\mathrm{h} / \mathrm{wk}$ of $\mathrm{MVPA}^{28}$. Women with 0 MET-h/wk of total PA (i.e., who reported rarely or never walking and no light PA or MVPA) were defined as being "physically inactive."

Covariates. Participants reported demographic characteristics, lifestyle behaviors, and medical history at baseline through questionnaires. Demographic characteristics included race/ethnicity, education, income, and marital status. Lifestyle behaviors included smoking and alcohol consumption. Trained clinic staff measured height and weight at baseline. Body mass index (BMI; $\mathrm{kg} / \mathrm{m}^{2}$ ) was calculated and categorized into established cutpoints: normal weight $\left(\leq 24.9 \mathrm{~kg} / \mathrm{m}^{2}\right)$, overweight $\left(25-29.9 \mathrm{~kg} / \mathrm{m}^{2}\right)$, and obese $\left(\geq 30 \mathrm{~kg} / \mathrm{m}^{2}\right)^{29}$. Additional baseline covariates were self-rated health, joint pain or stiffness, and hormone therapy use, which was defined according to self-reported use and participation in the hormone therapy trials. Depressive symptoms were measured using the Burnham scale ${ }^{30}$. The Medicare data file was used to collect information on age at TJR.

Information on chronic diseases associated with loss of mobility ${ }^{31,32,33}$, including coronary heart disease, stroke, congestive heart failure, peripheral arterial disease, diabetes, cancer, and hip fracture, was self-reported at baseline. Incident diseases were identified during study followup through periodic clinic visits and mailed questionnaires administered biannually to clinical trial participants and annually to observational study and extension study participants. All diseases, except for diabetes, were adjudicated by physician review of medical records. Diabetes was defined as self-reported physician diagnosis of diabetes treated with either oral medication or insulin, which has been previously validated ${ }^{34}$.

Outcomes. Women were classified as having survived to age 85 or died before this age. Deaths were verified by physician adjudication using hospital records, autopsy or coroner's reports, or death certificates. To ensure complete mortality followup, periodic linkage to the National Death Index was performed for all participants, including those lost to followup.

Late-life mobility status was assessed with the physical function subscale of the 36-item Short Form Health Survey ${ }^{35}$, which participants completed annually after 2005. Among women who survived to age 85 , mobility limitation was defined as reporting limitations in the ability to walk 1 block or climb 1 flight of stairs ${ }^{31,32}$. The most recent measures with the least missing data that were collected within 2 years of the 85 th birth year were

Personal non-commercial use only. The Journal of Rheumatology Copyright @ 2018 . All rights reserved. 
used. Three possible aging outcomes were defined, similar to previous aging studies $^{36,37}$ : survived to age 85 with mobility limitation; survived to age 85 with intact mobility (reference); or died before age 85 . The age of 85 was selected because in US census reports, individuals aged $\geq 85$ years comprise the "oldest-old" population, which is the fastest growing segment of the population aged $\geq 65$ years $^{38}$

Statistical analysis. Baseline characteristics were compared across quartiles of total leisure-time PA using chi-square tests for categorical variables, and ANOVA for normally distributed and Kruskal-Wallis tests for non-normally distributed continuous variables.

The analytic approach for this study was similar to that from previous prospective studies examining aging outcomes, in which the focus is not on associations with time to disability or time to mortality, but rather mobility at advanced age or death before advanced age $\mathrm{e}^{36,37}$. Multinomial logistic regression models were used to examine associations between PA variables and the mobility outcome. Separate models were fit for total leisure-time PA, MVPA, walking, and walking speed as the primary exposures. Analyses were conducted separately for THR and TKR. Multivariable models were adjusted for age at first THR or TKR, race/ethnicity, study membership (observational study or clinical trial), education, baseline marital status, baseline alcohol consumption, baseline smoking, baseline BMI, hormone therapy use, number of chronic diseases, baseline depression, and occurrence of a second THR (or TKR). Models for THR were also adjusted for use of TKR and vice versa. Additional models were adjusted for baseline mobility to determine whether this factor mediated associations between PA variables and late-life mobility. To test for linear trend associations, continuous measures of PA variables were included in multivariable models. Interactions between PA variables and age at TJR and BMI were also tested.

In sensitivity analyses, to check for potential bias due to missing late-life functional data, women who survived to age 85 but had missing mobility data were assumed to have late-life mobility limitation in the models. A sensitivity analysis excluding women who received a TJR within 2 years of the baseline study visit was also conducted to determine whether severe cases of hip or knee OA at the time of the baseline PA assessment biased findings. Finally, to determine whether the timing of PA assessment biased findings, additional models were adjusted for number of years between the PA questionnaire and TJR.

$\mathrm{P}$ values were 2 -sided and significant at $\mathrm{p}<0.05$. Statistical analyses were conducted using SAS Version 9.3 (SAS Institute Inc.).

\section{RESULTS}

The mean age at baseline was 69.5 years (SD 3.0, range 65-79) in the overall cohort. Women were followed for an average of 8.1 years (SD 3.5, range, 3-18) after TJR. Further, 94.9\% were white, $3.0 \%$ were African American, and 2.2\% were other racial/ethnic groups. In the THR cohort, $47.7 \%$ had mobility limitation at age $85,35.3 \%$ had intact mobility at age 85 , and $17.0 \%$ died before age 85 . The mean age at first THR was 77.7 years (SD 3.9, range 67-84). In total, $20.6 \%$ had a second THR, $4.8 \%$ had a revision hip procedure, and $17.8 \%$ had TKR. In the TKR cohort, $48.7 \%$ had mobility limitation at age $85,31.7 \%$ had intact mobility at age 85 , and $19.6 \%$ died before age 85 . The mean age at first TKR was 77.5 years (SD 4.0, range 67-84). Overall, $28.5 \%$ had a second TKR, $3.8 \%$ had a knee revision procedure, and $9.4 \%$ had THR.

At baseline, women with higher levels of total PA were more likely to be college graduates, have higher income, currently consume alcohol, and have excellent or very good self-rated health (Table 1). They were less likely to be obese, have depressive symptoms, have a history of chronic diseases, or report severe joint pain or stiffness at baseline. Women with lower PA levels were more likely to have mobility limitation at baseline. Half of women who reported not participating in any PA had baseline mobility limitation.

Relative to women with THR with the highest level of total PA (> 17.42 MET-h/wk), physically inactive women (OR 2.36, 95\% CI 1.30-4.26) had the highest odds of mobility limitation at age 85 ( $\mathrm{p}$ for trend $<0.001$ ) in the multivariable model (Table 2). Compared with women with THR who reported $\geq 15$ MET-h/wk of MVPA, the odds of mobility limitation were significantly higher for lower levels of MVPA and were highest in women with no MVPA (OR $2.00,95 \%$ CI $1.24-3.22, \mathrm{p}$ for trend $<0.001$ ). Relative to women with the greatest amount of walking ( $>6.25$ MET-h/wk), the odds of mobility limitation were strongest among women who did not engage in any walking (OR 1.81, $95 \%$ CI $1.20-2.72, \mathrm{p}$ for trend $=0.003$ ). Further, the odds of mobility limitation were about 2-fold higher among women who reported casual (i.e., slower than normal) compared with fast walking speed ( $\mathrm{p}$ for trend $=0.02$ ). There were significant dose-response associations of total PA, MVPA, walking, and walking speed with death before age 85 . In models adjusting for baseline mobility, findings were no longer significant (data not shown).

Inactive women with TKR had the highest odds of mobility limitation at age 85 (OR 1.68, 95\% CI 1.15-2.45) and dying before age 85 (OR 1.79, 95\% CI 1.09-2.95) compared with women who were the most physically active before TKR ( $\mathrm{p}$ for trend for mobility $=0.007$ and $\mathrm{p}$ for trend for death $=0.02$; Table 3). Compared with women engaging in $\geq 15 \mathrm{MET}$-h/week of MVPA, those with lower levels of MVPA had significantly increased odds of mobility limitation ( $\mathrm{p}$ for trend $=0.002$ ). Women with no MVPA had a 2-fold increased risk of dying before 85 years (OR $2.24,95 \%$ CI $1.47-3.42$, p for trend $=0.01$ ). Women with casual relative to fast walking speed had increased odds of mobility limitation ( $\mathrm{p}$ for trend $=0.007$ ) and death ( $\mathrm{p}$ for trend $<0.001$ ). After adjusting for baseline mobility, PA variables were no longer significantly associated with late-life mobility or death (data not shown).

Findings did not vary by age at TJR or BMI. In sensitivity analyses, findings were not altered after excluding women who underwent a THR or TKR within 2 years of the baseline study visit. In sensitivity analyses, assuming that women who survived to age 85 with missing data for mobility had late-life mobility limitation in the multivariable models, findings were similar. Adjustment for number of years between PA assessment and TJR did not alter the findings (data not shown).

\section{DISCUSSION}

In our prospective study, women who engaged in lower amounts of total PA and MVPA before TJR for hip or knee

Personal non-commercial use only. The Journal of Rheumatology Copyright $\subset$ $\subset$ 2018. All rights reserved 
Table 1. Baseline characteristics by total physical activity among older women with total joint replacement for osteoarthritis. Values are n (\%) unless otherwise specified.

\begin{tabular}{|c|c|c|c|c|c|}
\hline \multirow[t]{2}{*}{ Characteristics } & \multirow[b]{2}{*}{$0, \mathrm{n}=371$} & \multicolumn{2}{|c|}{ Total Physical Activity, MET-hrs/week } & \multirow[b]{2}{*}{$>17.42, \mathrm{n}=819$} & \multirow[t]{2}{*}{$\mathrm{p}$} \\
\hline & & $>0$ to $7, \mathrm{n}=789$ & $>7$ to $17.42, \mathrm{n}=839$ & & \\
\hline Age, yrs, mean (SD) & $69.8(3.1)$ & $69.7(2.9)$ & $69.4(2.9)$ & $69.4(2.9)$ & 0.01 \\
\hline White & $352(95.1)$ & $735(93.4)$ & $795(95.1)$ & $783(96.0)$ & \\
\hline African American & $9(2.4)$ & $32(4.1)$ & $24(2.9)$ & $18(2.2)$ & 0.36 \\
\hline Other & $9(2.4)$ & $20(2.5)$ & $17(2.0)$ & $15(1.8)$ & \\
\hline High school & $85(23.0)$ & $153(19.5)$ & $114(13.6)$ & $103(12.6)$ & \\
\hline Some college & $151(40.8)$ & $296(37.7)$ & $288(34.5)$ & $267(32.7)$ & $<0.001$ \\
\hline College graduate & $120(32.4)$ & $306(38.9)$ & $413(49.4)$ & $427(52.3)$ & \\
\hline Income, annual & $\mathrm{n}=345$ & $\mathrm{n}=734$ & $\mathrm{n}=791$ & $\mathrm{n}=767$ & \\
\hline$<\$ 20,000$ & $69(20.0)$ & $116(15.8)$ & $107(13.5)$ & $75(9.8)$ & \\
\hline$\$ 20,000-\$ 50,000$ & $174(50.4)$ & $391(53.3)$ & $401(50.7)$ & $370(48.2)$ & $<0.001$ \\
\hline Divorced/separated & $37(10.0)$ & $69(8.8)$ & $92(11.0)$ & $73(8.9)$ & \\
\hline Never married & $14(3.8)$ & $35(4.5)$ & $32(3.8)$ & $25(3.1)$ & \\
\hline Alcohol consumption & $\mathrm{n}=367$ & $\mathrm{n}=783$ & $\mathrm{n}=839$ & $\mathrm{n}=816$ & \\
\hline Non-drinker & $36(9.8)$ & $80(10.2)$ & $87(10.4)$ & $61(7.5)$ & \\
\hline Past drinker & $83(22.6)$ & $128(16.4)$ & $117(14.0)$ & $83(10.2)$ & $<0.001$ \\
\hline Current drinker & $248(67.6)$ & $575(73.4)$ & $635(75.7)$ & $672(82.4)$ & \\
\hline Smoking status & $\mathrm{n}=362$ & $\mathrm{n}=783$ & $\mathrm{n}=830$ & $\mathrm{n}=816$ & \\
\hline Never smoked & $190(52.5)$ & $421(53.8)$ & $440(53.0)$ & $385(47.2)$ & \\
\hline Past smoker & $158(43.7)$ & $329(42.0)$ & $368(44.3)$ & $408(50.0)$ & 0.03 \\
\hline Current smoker & $14(3.9)$ & $33(4.2)$ & $22(2.7)$ & $23(2.8)$ & \\
\hline $\mathrm{BMI}, \mathrm{kg} / \mathrm{m}^{2}$ & $\mathrm{n}=367$ & $\mathrm{n}=783$ & $\mathrm{n}=831$ & $\mathrm{n}=810$ & \\
\hline Normal weight & $53(14.4)$ & $164(21.0)$ & $226(27.2)$ & $318(39.3)$ & \\
\hline Very good & $119(32.3)$ & $314(40.1)$ & $364(43.8)$ & $358(44.1)$ & $<0.001$ \\
\hline Good & $162(43.9)$ & $339(43.2)$ & $291(35.0)$ & $241(29.7)$ & \\
\hline Fair/poor & $59(16.0)$ & $62(7.9)$ & $62(7.5)$ & $29(3.6)$ & \\
\hline Burnham depression scale score $\geq 0.06$ & $\mathrm{n}=361,35(9.7)$ & $\mathrm{n}=773,65(8.4)$ & $\mathrm{n}=823,62(7.5)$ & $\mathrm{n}=794,44(5.5)$ & 0.05 \\
\hline History of chronic diseases ${ }^{\mathrm{a}}$ & $\mathrm{n}=371$ & $\mathrm{n}=789$ & $\mathrm{n}=839$ & $\mathrm{n}=819$ & \\
\hline CHD & $41(11.1)$ & $85(10.8)$ & $86(10.3)$ & $64(7.8)$ & 0.15 \\
\hline Stroke & $32(8.6)$ & $66(8.4)$ & $55(6.6)$ & $60(7.3)$ & 0.46 \\
\hline $\mathrm{CHF}$ & $30(8.1)$ & $39(4.9)$ & $37(4.4)$ & $21(2.6)$ & $<0.001$ \\
\hline PAD & $22(5.9)$ & $30(3.8)$ & $32(3.8)$ & $27(3.3)$ & 0.18 \\
\hline Diabetes & $75(20.2)$ & $137(17.4)$ & $102(12.2)$ & $118(14.4)$ & $<0.001$ \\
\hline Cancer & $110(29.7)$ & $199(25.2)$ & $236(28.1)$ & $233(28.5)$ & 0.33 \\
\hline Hip fracture & $26(7.0)$ & $52(6.6)$ & $49(5.8)$ & $40(4.9)$ & 0.39 \\
\hline Any disease & $226(60.9)$ & $436(55.3)$ & $431(51.4)$ & $420(51.3)$ & 0.006 \\
\hline Mobility limitation & $\mathrm{n}=368,185(50.3)$ & $\mathrm{n}=781,243(31.1)$ & $\mathrm{n}=830,200(24.1)$ & $\mathrm{n}=809,127(15.7)$ & $<0.001$ \\
\hline Joint pain & $\mathrm{n}=369$ & $\mathrm{n}=782$ & $\mathrm{n}=835$ & $\mathrm{n}=812$ & \\
\hline None & $32(8.7)$ & $92(11.8)$ & $104(12.5)$ & $139(17.1)$ & \\
\hline Mild & $144(39.0)$ & $335(42.8)$ & $406(48.6)$ & $397(48.9)$ & $<0.001$ \\
\hline Moderate & $129(35.0)$ & $278(35.6)$ & $249(29.8)$ & $224(27.6)$ & \\
\hline Severe & $64(17.3)$ & $77(9.9)$ & $76(9.1)$ & $52(6.4)$ & \\
\hline
\end{tabular}

Sample sizes for variables in each column do not sum to total because of missing data. ${ }^{\text {a }}$ Includes baseline and incident chronic diseases. MET: metabolic equivalent of task; BMI: body mass index; CHD: coronary heart disease; CHF: congestive heart failure; PAD: peripheral arterial disease. 
Table 2. Multivariable associations of physical activity with mobility among women with total hip replacement for osteoarthritis ${ }^{\mathrm{a}}$. Values are $\mathrm{n} / \mathrm{n}(\%)$ unless otherwise specified.

\begin{tabular}{|c|c|c|c|c|}
\hline Variables & $\begin{array}{l}\text { No. Survived to } \\
85 \text { Yrs with Mobility } \\
\text { Limitation/total }\end{array}$ & $\begin{array}{c}\text { Survived to } 85 \\
\text { Yrs with Mobility } \\
\text { Limitation }^{\text {b }}, \text { OR }(95 \% \mathrm{CI})\end{array}$ & $\begin{array}{c}\text { No. Died before } \\
85 \mathrm{Yrs} / \text { total }\end{array}$ & $\begin{array}{c}\text { Died before } 85^{\mathrm{b}} \\
\text { Yrs, OR }(95 \% \mathrm{CI})\end{array}$ \\
\hline \multicolumn{5}{|c|}{ Total physical activity, MET-hrs/week ${ }^{\mathrm{c}}$} \\
\hline 0 & $67 / 117(57.3)$ & $2.36(1.30-4.26)$ & 25/117 (21.4) & $2.18(0.98-4.84)$ \\
\hline$>0$ to 7 & $149 / 286(52.1)$ & $1.74(1.16-2.61)$ & $59 / 286(20.6)$ & $2.36(1.32-4.22)$ \\
\hline$>7$ to 17.42 & $151 / 320(47.2)$ & $1.23(0.85-1.78)$ & $49 / 320(15.3)$ & $1.49(0.85-2.62)$ \\
\hline$>17.42$ & $126 / 311(40.5)$ & $1[$ Ref $]$ & $43 / 311(13.8)$ & $1[$ Ref $]$ \\
\hline \multicolumn{5}{|c|}{ Moderate to vigorous physical activity, MET-hrs/week ${ }^{\mathrm{d}}$} \\
\hline 0 & $107 / 198(54.0)$ & $2.00(1.24-3.22)$ & $41 / 198(20.7)$ & $2.03(1.06-3.91)$ \\
\hline$>0$ to $<7.5$ & $145 / 283(51.2)$ & $1.83(1.23-2.71)$ & $54 / 283(19.1)$ & $2.12(1.20-3.74)$ \\
\hline 7.5 to $<15$ & $114 / 228(50.0)$ & $1.63(1.09-2.43)$ & $34 / 228(14.9)$ & $2.00(1.09-2.43)$ \\
\hline$\geq 15$ & $127 / 325(39.1)$ & $1[$ Ref $]$ & $47 / 325(14.5)$ & $1[$ Ref $]$ \\
\hline \multicolumn{5}{|l|}{ Walking ${ }^{\mathrm{e}}$} \\
\hline 0 & $166 / 312(53.2)$ & $1.81(1.20-2.72)$ & $64 / 312(20.5)$ & $2.05(1.13-3.72)$ \\
\hline$>0$ to 2.5 & $102 / 211(48.3)$ & $1.58(1.02-2.45)$ & $47 / 211(22.3)$ & $2.65(1.42-4.95)$ \\
\hline$>2.5$ to 6.25 & $102 / 224(45.5)$ & $1.15(0.77-1.72)$ & $33 / 224(14.7)$ & $1.20(0.64-2.27)$ \\
\hline$>6.25$ & $123 / 287(42.9)$ & $1[$ Ref $]$ & $32 / 287(11.2)$ & $1[$ Ref $]$ \\
\hline \multicolumn{5}{|l|}{ Walking speed ${ }^{\mathrm{f}}$} \\
\hline Casual, slower than normal & $103 / 210(49.1)$ & $1.90(1.13-3.20)$ & $54 / 210(25.7)$ & $2.08(1.03-4.19)$ \\
\hline Average or normal & $227 / 468(48.5)$ & $1.24(0.83-1.83)$ & $59 / 468(12.6)$ & $0.91(0.50-1.65)$ \\
\hline Fast & $79 / 196(40.3)$ & $1[$ Ref $]$ & $27 / 196(13.8)$ & $1[$ Ref $]$ \\
\hline
\end{tabular}

\footnotetext{
${ }^{a}$ Reference group is survived to age 85 years with intact mobility. ${ }^{b}$ Adjusted for age at first total hip replacement, study membership, education, race/ethnicity, baseline marital status, baseline alcohol consumption, baseline smoking, baseline body mass index, total no. chronic diseases, hormone therapy use, baseline depression, second total hip replacement, and total knee replacement. ${ }^{\mathrm{c}} \mathrm{N}$ for multivariable analyses $=960$. $\mathrm{P}$ for trend (mobility limitation) $=<0.001 ; \mathrm{p}$ for trend $($ death $)=0.02 .{ }^{\mathrm{d}} \mathrm{N}$ for multivariable analyses $=960$. P for trend (mobility limitation) $=<0.001 ; \mathrm{p}$ for trend $($ death $)=0.03 .{ }^{\mathrm{e}} \mathrm{N}$ for multivariable analyses $=960 . \mathrm{P}$ for trend $($ mobility limitation $)=0.003 ; \mathrm{p}$ for trend $($ death $)=0.01 .{ }^{\mathrm{f}} \mathrm{N}$ for multivariable analyses $=820$. P for trend $($ mobility limitation $)=0.02 ; \mathrm{p}$ for trend $($ death $)=0.03$. MET: metabolic equivalent of task.
}

OA had increased risk of late-life mobility limitation as well as death. Risks for poor mobility and death were also significantly increased among women with slower walking speed. These findings were independent of demographic characteristics, lifestyle behaviors, BMI, and chronic conditions that may impair function. Our data underscore that a large proportion of women with hip or knee OA may reach old age with poor mobility despite TJR.

Among the general population, PA levels measured in midlife or early old age predicted mobility and physical functioning later in life $\mathrm{e}^{20,21,22,23,24}$. A community-based study among older men and women observed that regular PA (i.e., walking, gardening, or vigorous exercise) at least 3 times/week was associated with maintaining the ability to walk a half mile or up and down stairs without help 4 years later ${ }^{24}$. Among men and women aged 70 to 89 years, a PA intervention compared with a health education program was associated with decreased risk of developing mobility disability, defined as the inability to walk $400 \mathrm{~m}$ without help ${ }^{22}$. Our findings build upon previous research by examining a cohort consisting exclusively of patients with $\mathrm{OA}$, an important consideration given that $\mathrm{OA}$ is a leading cause of disability among older adults ${ }^{1}$.

Although there is some evidence that PA may improve physical function before $\mathrm{TJR}^{14}$, it is unclear whether it optimizes longterm postoperative outcomes, because most studies have been limited by short postsurgery followup periods ${ }^{15,16,17,39,40}$. A 6-week exercise intervention immediately before THR or TKR did not improve functional outcomes at 6 months after surgery ${ }^{15}$. However, the longterm effectiveness of PA in minimizing disability among patients with OA may depend on remaining physically active over time. For example, hip and knee OA patients who remained adherent to recommended home exercises for up to 5 years showed greater improvements in physical function ${ }^{11}$. The dose-response associations of total PA, MVPA, and walking with mobility in old age and death in our study suggest that there may be longterm advantages in being physically active for women with hip or knee OA. Further, the stronger associations of PA with mobility limitation among women with THR than with TKR support future studies examining whether PA confers greater benefit for patients with hip or knee OA.

Some studies showed that patient PA levels do not change postoperatively, despite evidence that PA after TJR is associated with improved function $39,41,42,43$. The research to date demonstrates that there may be advantages in PA both pre- and postoperatively. Accordingly, instilling behavioral change among TJR patients to participate in greater amounts of PA may be important for improvement of functional health in the long term.

We found that women with slower self-reported walking Personal non-commercial use only. The Journal of Rheumatology Copyright $\subset$ 2018. All rights reserved. 
Table 3. Multivariable associations of physical activity with mobility among women with total knee replacement for osteoarthritis ${ }^{\mathrm{a}}$. Values are $\mathrm{n} / \mathrm{n}(\%)$ unless otherwise specified.

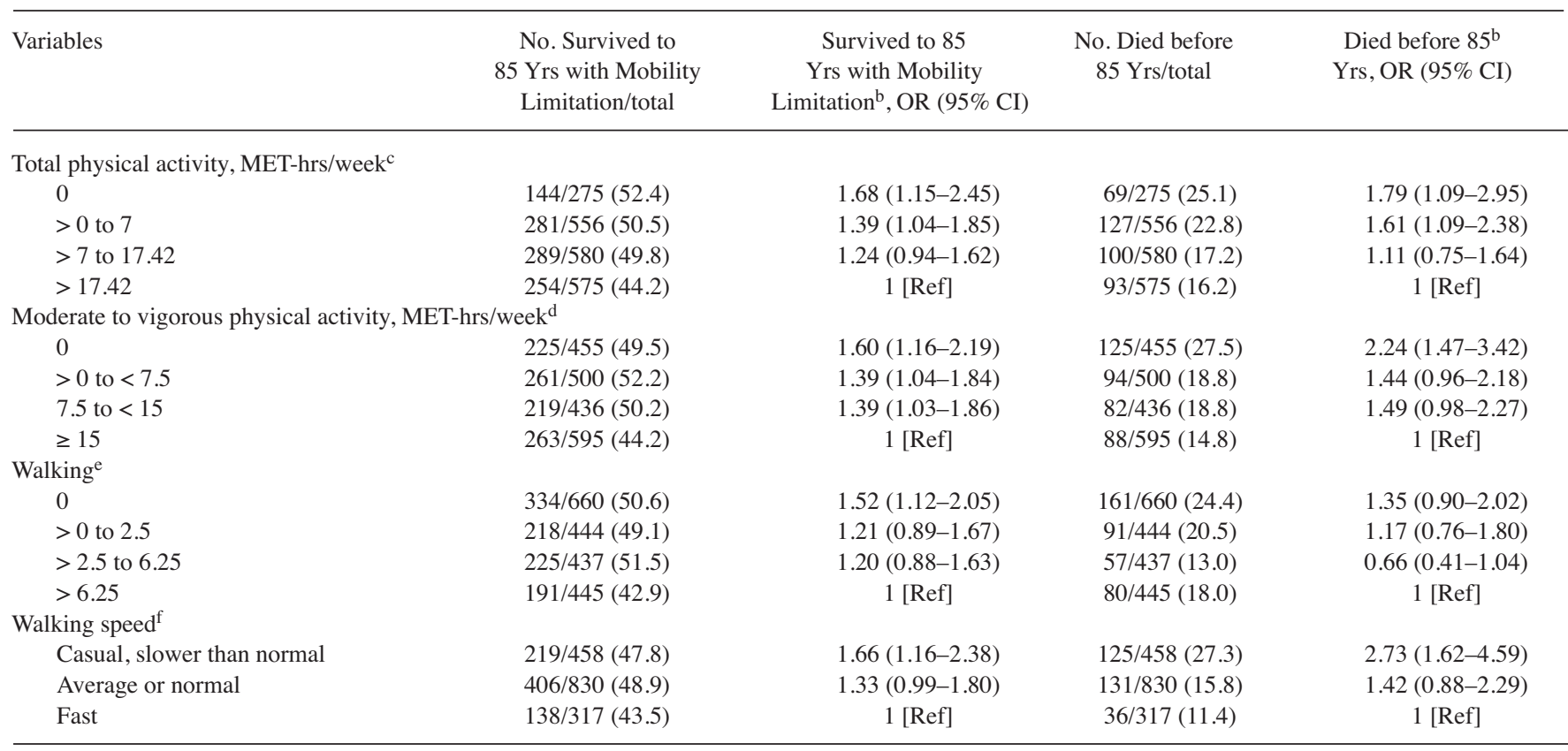

\footnotetext{
${ }^{a}$ Reference group is survived to age 85 years with intact mobility. ${ }^{b}$ Adjusted for age at first total knee replacement, study membership, education, race/ethnicity, baseline marital status, baseline alcohol consumption, baseline smoking, baseline body mass index, total no. chronic diseases, hormone therapy use, baseline depression, second total knee replacement, and total hip replacement. ${ }^{\mathrm{c}} \mathrm{N}$ for multivariable analyses $=1863$. $\mathrm{P}$ for trend (mobility limitation) $=0.007$; $\mathrm{p}$ for trend $($ death $)=0.02 .^{\mathrm{d}} \mathrm{N}$ for multivariable analyses $=1863$. P for trend (mobility limitation) $=0.002 ; \mathrm{p}$ for trend $($ death $)=0.01 .^{\mathrm{e}} \mathrm{N}$ for multivariable analyses $=1863$. P for trend (mobility limitation $)=0.01 ; \mathrm{p}$ for trend $($ death $)=0.25 .{ }^{\mathrm{f}} \mathrm{N}$ for multivariable analyses $=1510 . \mathrm{P}$ for trend $($ mobility limitation $)=0.007 ; \mathrm{p}$ for trend (death) $=<0.001$. MET: metabolic equivalent of task.
}

speed had increased risk of mobility limitation and death. Faster walking speed has been associated with decreased risk of knee $\mathrm{OA}^{44}$. Among non-disabled older adults, walking speed is a predictor of future disability and mortality ${ }^{45}$. Our results suggest that walking speed may also be a marker of future aging outcomes among OA patients with TJR.

The benefits of PA in the setting of OA include attenuation of joint loading, maintenance of joint stability, and assistance with joint motion and elasticity of periarticular tissues, all of which are important to maintaining function ${ }^{1}$. Extended periods of inactivity due to OA increase risk of obesity, cardiovascular disease, and other conditions that may lead to poor function ${ }^{1}$; however, our findings were independent of these diseases. All women who joined the WHI were ambulatory at baseline. Nonetheless, we observed that women who were less physically active were more likely to have difficulty walking 1 block or climbing 1 flight of stairs at baseline. Moreover, after controlling for baseline mobility, dose-response associations of PA with late-life mobility limitation and death were no longer significant. Because baseline PA and mobility were both assessed at the same study visit, we could not determine whether PA resulted in better mobility before TJR and consequently in late life. Notably, it was previously shown that OA patients with better preoperative function achieved greater improvements in function after THR and TKR; however, factors such as PA that could result in better preoperative function were not assessed $^{46}$.

Limitations of our study include self-reported PA and lack of information on strength, resistance, and flexibility exercises. Self-reported PA correlates weakly with objectively measured PA, which may provide a better estimate of time spent in activities of varying intensity ${ }^{47}$. Although we categorized PA levels resulting in loss of power, we also tested linear trend associations using continuous measures. We lacked information on specific types (e.g., household or work-related) of activity. Self-reported total energy expenditure from the WHI PA questionnaire correlates weakly with objectively measured total energy expenditure, and thus may be prone to measurement error ${ }^{48}$. PA was collected at baseline and several years before TJR. However, this approach is consistent with previous studies linking PA patterns in midlife and early old age to late-life disability ${ }^{20,21,22,23,24}$. Our study consisted only of fee-for-service beneficiaries, thus findings may not be generalized to women enrolled in Medicare managed care plans. In the WHI, fee-for-service beneficiaries are more likely to be white and of a higher socioeconomic status. Because $95 \%$ of women in this subcohort of WHI women were white, we could not evaluate ethnic differences. Many women who survived to age 85 had missing infor-

Personal non-commercial use only. The Journal of Rheumatology Copyright @ 2018 . All rights reserved. 
mation on late-life mobility. However, after fitting models assuming that these women had late-life mobility limitation, findings were similar, suggesting that our findings were not biased by missing outcome data. Our study was focused on examination of healthy aging outcomes in TJR recipients and did not address whether PA levels were associated with increased risk of mortality among TJR survivors.

A strength of our study is the population-based sample of women followed for a long period of time after TJR, which provided the unique opportunity to assess late-life functional outcomes. The combination of WHI and Medicare data was a rich resource to examine the association of PA with late-life functional outcomes and death.

Women with higher levels of total PA, MVPA, and walking, as well as faster walking speed, before TJR for hip or knee OA were more likely to have intact mobility in late life and have decreased risk of death. Additional studies are warranted to determine whether engaging in PA before TJR reduces risk of disability among patients with severe hip or knee OA.

\section{ACKNOWLEDGMENT}

We acknowledge the following Women's Health Initiative Investigators: Program Office: Jacques Rossouw, Shari Ludlam, Dale Burwen, Joan McGowan, Leslie Ford, and Nancy Geller (US National Heart, Lung, and Blood Institute, Bethesda, Maryland); Clinical Coordinating Center: Garnet Anderson, Ross Prentice, Andrea LaCroix, and Charles Kooperberg (Fred Hutchinson Cancer Research Center, Seattle, Washington); Investigators and Academic Centers: JoAnn E. Manson (Brigham and Women's Hospital, Harvard Medical School, Boston, Massachusetts), Barbara V. Howard (MedStar Health Research Institute/Howard University, Washington, DC), Marcia L. Stefanick (Stanford Prevention Research Center, Stanford, California); Rebecca Jackson (The Ohio State University, Columbus, Ohio), Cynthia A. Thomson (University of Arizona, Tucson/Phoenix, Arizona), Jean Wactawski-Wende (State University of New York at Buffalo, Buffalo, New York), Marian Limacher (University of Florida, Gainesville/Jacksonville, Florida), Robert Wallace (University of Iowa, Iowa City/Davenport, Iowa), Lewis Kuller (University of Pittsburgh, Pittsburgh, Pennsylvania); Sally Shumaker (Wake Forest University School of Medicine, Winston-Salem, North Carolina).

\section{ONLINE SUPPLEMENT}

Supplementary material accompanies the online version of this article.

\section{REFERENCES}

1. Felson DT, Lawrence RC, Dieppe PA, Hirsch R, Helmick CG, Jordan JM, et al. Osteoarthritis: new insights. Part 1: the disease and its risk factors. Ann Intern Med 2000;133:635-46.

2. Hunter DJ, Schofield D, Callander E. The individual and socioeconomic impact of osteoarthritis. Nat Rev Rheumatol 2014; 10:437-41.

3. George LK, Ruiz D, Sloan FA. The effects of total knee arthroplasty on physical functioning in the older population. Arthritis Rheum 2008;58:3166-71.

4. George LK, Ruiz D Jr, Sloan FA. The effects of total hip arthroplasty on physical functioning in the older population. J Am Geriatr Soc 2008;56:1057-62.

5. Agency for Healthcare Research and Quality. HCUP projections: mobility/orthopedic procedures 2003 to 2012. United States, September 2012. Rockville: Agency for Healthcare Research and Quality; 2012: HCUP publication no. 2012-03.
6. Kurtz S, Ong K, Lau E, Mowat F, Halpern M. Projections of primary and revision hip and knee arthroplasty in the United States from 2005 to 2030. J Bone Joint Surg Am 2007;89:780-5.

7. Westby MD. A health professional's guide to exercise prescription for people with arthritis: a review of aerobic fitness activities. Arthritis Rheum 2001;45:501-11.

8. Penninx BW, Messier SP, Rejeski WJ, Williamson JD, DiBari M, Cavazzini $\mathrm{C}$, et al. Physical exercise and the prevention of disability in activities of daily living in older persons with osteoarthritis. Arch Intern Med 2001;161:2309-16.

9. Juhl C, Christensen R, Roos EM, Zhang W, Lund H. Impact of exercise type and dose on pain and disability in knee osteoarthritis: a systematic review and meta-regression analysis of randomized controlled trials. Arthritis Rheumatol 2014;66:622-36.

10. Ettinger WH Jr, Burns R, Messier SP, Applegate W, Rejeski WJ, Morgan T, et al. A randomized trial comparing aerobic exercise and resistance exercise with a health education program in older adults with knee osteoarthritis. The Fitness Arthritis and Seniors Trial (FAST). JAMA 1997;277:25-31.

11. Pisters MF, Veenhof C, Schellevis FG, Twisk JW, Dekker J, De Bakker DH. Exercise adherence improving long-term patient outcome in patients with osteoarthritis of the hip and/or knee. Arthritis Care Res 2010;62:1087-94.

12. van Baar ME, Assendelft WJ, Dekker J, Oostendorp RA, Bijlsma JW. Effectiveness of exercise therapy in patients with osteoarthritis of the hip or knee: a systematic review of randomized clinical trials. Arthritis Rheum 1999;42:1361-9.

13. Gill SD, McBurney H. Does exercise reduce pain and improve physical function before hip or knee replacement surgery? A systematic review and meta-analysis of randomized controlled trials. Arch Phys Med Rehabil 2013;94:164-76.

14. Henschke N, Diong J. Exercise reduces pain and improves physical function for people awaiting hip replacement surgery. Br J Sports Med 2014;48:477-8

15. Rooks DS, Huang J, Bierbaum BE, Bolus SA, Rubano J, Connolly $\mathrm{CE}$, et al. Effect of preoperative exercise on measures of functional status in men and women undergoing total hip and knee arthroplasty. Arthritis Rheum 2006;55:700-8.

16. Poortinga S, van den Akker-Scheek I, Bulstra SK, Stewart RE, Stevens M. Preoperative physical activity level has no relationship to the degree of recovery one year after primary total hip or knee arthroplasty: a cohort study. PLoS One 2014;9:e115559.

17. Gilbey HJ, Ackland TR, Wang AW, Morton AR, Trouchet T, Tapper J. Exercise improves early functional recovery after total hip arthroplasty. Clin Orthop Relat Res 2003;408:193-200.

18. D'Lima DD, Colwell CW Jr, Morris BA, Hardwick ME, Kozin F. The effect of preoperative exercise on total knee replacement outcomes. Clin Orthop Relat Res 1996;326:174-82.

19. Rantakokko M, Mänty M, Rantanen T. Mobility decline in old age. Exerc Sport Sci Rev 2013;41:19-25.

20. Patel KV, Coppin AK, Manini TM, Lauretani F, Bandinelli S, Ferrucci L, et al. Midlife physical activity and mobility in older age: the InCHIANTI Study. Am J Prev Med 2006;31:217-24.

21. Stenholm S, Koster A, Valkeinen H, Patel KV, Bandinelli S, Guralnik JM, et al. Association of physical activity history with physical function and mortality in old age. J Gerontol A Biol Sci Med Sci 2016;71:496-501.

22. Gill TM, Guralnik JM, Pahor M, Church T, Fielding RA, King AC, et al; LIFE Study Investigators. Effect of structured physical activity on overall burden and transitions between states of major mobility disability in older persons: secondary analysis of a randomized trial. Ann Intern Med 2016;165:833-40.

23. Chang M, Saczynski JS, Snaedal J, Bjornsson S, Einarsson B, Garcia M, et al. Midlife physical activity preserves lower extremity function in older adults: Age Gene/Environment 
Susceptibility-Reykjavik Study. J Am Geriatr Soc 2013;61:237-42.

24. LaCroix AZ, Guralnik JM, Berkman LF, Wallace RB, Satterfield S. Maintaining mobility in late life. II. Smoking, alcohol consumption, physical activity, and body mass index. Am J Epidemiol 1993;137:858-69.

25. The Women's Health Initiative Study Group. Design of the Women's Health Initiative clinical trial and observational study. Control Clin Trials 1998;19:61-109.

26. Meyer AM, Evenson KR, Morimoto L, Siscovick D, White E. Test-retest reliability of the Women's Health Initiative physical activity questionnaire. Med Sci Sports Exerc 2009;41:530-8.

27. Ainsworth BE, Haskell WL, Whitt MC, Irwin ML, Swartz AM, Strath SJ, et al. Compendium of physical activities: an update of activity codes and MET intensities. Med Sci Sports Exerc 2000;32 Suppl:S498-504.

28. Nelson ME, Rejeski WJ, Blair SN, Duncan PW, Judge JO, King AC, et al. Physical activity and public health in older adults. Med Sci Sports Exerc 2007;39:1435-45.

29. National Institutes of Health. Clinical guidelines on the identification, evaluation, and treatment of overweight and obesity in adults - the evidence report. Obes Res 1998;6:515-2095.

30. Burnam MA, Wells KB, Leake B, Landsverk J. Development of a brief screening instrument for detecting depressive disorders. Med Care 1988;26:775-89.

31. Guralnik JM, LaCroix AZ, Abbott RD, Berkman LF, Satterfield S, Evans DA, et al. Maintaining mobility in late life. I. Demographic characteristics and chronic conditions. Am J Epidemiol 1993;137:845-57.

32. Houston DK, Ding J, Nicklas BJ, Harris TB, Lee JS, Nevitt MC, et al; Health ABC Study. Overweight and obesity over the adult life course and incident mobility limitation in older adults: the health, aging and body composition study. Am J Epidemiol 2009; 169:927-36.

33. Kopelman P. Health risks associated with overweight and obesity. Obes Rev 2007;8 Suppl 1:13-17.

34. Margolis KL, Lihong Qi, Brzyski R, Bonds DE, Howard BV, Kempainen S, et al; Women Health Initiative Investigators. Validity of diabetes self-reports in the Women's Health Initiative: comparison with medication inventories and fasting glucose measurements. Clin Trials 2008;5:240-7.

35. Ware JE Jr, Sherbourne CD. The MOS 36-item short-form health survey (SF-36). I. Conceptual framework and item selection. Med Care 1992;30:473-83.

36. Willcox BJ, He Q, Chen R, Yano K, Masaki KH, Grove JS, et al. Midlife risk factors and healthy survival in men. JAMA 2006;296:2343-50.
37. Rillamas-Sun E, LaCroix AZ, Waring ME, Kroenke CH, LaMonte MJ, Vitolins MZ, et al. Obesity and late-age survival without major disease or disability in older women. JAMA Intern Med 2014;174:98-106

38. United States Census Bureau. 65+ in the United States: 2010. United States, June 2014. Suitland: United States Census Bureau; 2014; USCB publication no. P23-212.

39. Zech A, Hendrich S, Pfeifer K. Association between exercise therapy dose and functional improvements in the early postoperative phase after hip and knee arthroplasty: An observational study. PM R 2015;7:1064-72.

40. Kwok IH, Paton B, Haddad FS. Does pre-operative physiotherapy improve outcomes in primary total knee arthroplasty? - A systematic review. J Arthroplasty 2015;30:1657-63.

41. Harding P, Holland AE, Delany C, Hinman RS. Do activity levels increase after total hip and knee arthroplasty? Clin Orthop Relat Res 2014;472:1502-11.

42. Arnold JB, Walters JL, Ferrar KE. Does physical activity increase after total hip or knee arthroplasty for osteoarthritis? A systematic review. J Orthop Sports Phys Ther 2016;46:431-42.

43. Kuster MS. Exercise recommendations after total joint replacement: a review of the current literature and proposal of scientifically based guidelines. Sports Med 2002;32:433-45.

44. Purser JL, Golightly YM, Feng Q, Helmick CG, Renner JB, Jordan $\mathrm{JM}$. Association of slower walking speed with incident knee osteoarthritis-related outcomes. Arthritis Care Res 2012; 64:1028-35.

45. Abellan van Kan G, Rolland Y, Andrieu S, Bauer J, Beauchet O, Bonnefoy M, et al. Gait speed at usual pace as a predictor of adverse outcomes in community-dwelling older people an International Academy on Nutrition and Aging (IANA) Task Force. J Nutr Health Aging 2009;13:881-9.

46. Fortin PR, Clarke AE, Joseph L, Liang MH, Tanzer M, Ferland D, et al. Outcomes of total hip and knee replacement: Preoperative functional status predicts outcomes at six months after surgery. Arthritis Rheum 1999;42:1722-8.

47. Dyrstad SM, Hansen BH, Holme IM, Anderssen SA. Comparison of self-reported versus accelerometer-measured physical activity. Med Sci Sports Exerc 2014;46:99-106.

48. Neuhouser ML, Di C, Tinker LF, Thomson C, Sternfeld B, Mossavar-Rahmani Y, et al. Physical activity assessment: biomarkers and self-report of activity-related energy expenditure in the WHI. Am J Epidemiol 2013;177:576-85. 